\title{
The use of clamped drainage to reduce blood loss in total hip arthroplasty
}

\author{
Jian-gang $\mathrm{Cao}^{1+}{ }^{1}$ Lei Wang $^{2+}$ and Jun $\mathrm{Liu}^{2 *}$
}

\begin{abstract}
Background: Drainage is a routine practice used to reduce hematoma and blood loss following total hip arthroplasty. The aim of this study was to assess the effect of clamped drainage on blood loss and wound healing after total hip arthroplasty.

Methods: A prospective cohort of 44 patients with hip osteoarthritis or femur head necrosis undergoing total hip arthroplasty was randomized equally into two groups: 6-h postoperative clamped or non-clamped suction tube drainage. Body mass index, gender distribution, preoperative hemoglobin, hip pathology, and affected side were comparable between the two groups. Blood loss, hemoglobin levels, and wound healing complications were recorded and compared between groups.

Results: The drainage blood loss and calculated blood loss volumes were higher for the non-clamped group. About $100 \mathrm{~mL}$ more blood loss was noticed in the non-clamped group. There was no significant difference in adverse events or need for transfusion.

Conclusions: The present study showed a statistically significant reduction in postoperative drainage amount between clamped and unclamped drainage groups, but this difference was not large enough to warrant increased blood transfusion requirements in patients with unclamped drainage. Further studies are essential to define the critical period of clamping that is compatible with the dual objectives of reduced blood loss and lack of wound complications from hematoma.
\end{abstract}

Keywords: Total hip arthroplasty, Clamped drainage, Blood loss, Wound complications

\section{Introduction}

Total hip arthroplasty (THA) is a successful and widely used method to treat hip disorders such as hip osteoarthritis (OA) and femoral head necrosis.THA can relieve pain, correct deformity, and restore and improve joint movement, making it widely performed by surgeons and accepted by patients. Due to the extensive soft tissue and bone dissection, patients undergoing THA are prone to between 1000 and $2000 \mathrm{~mL}$ of blood loss [1-3]. Hematomas are inevitable to a certain extent as complete hemostasis is difficult when the medullary canal is exposed, increasing wound tension, decreasing tissue perfusion, resulting in anemia, and providing an ideal medium for bacterial culture, all of which work against wound healing. Prolonged drainage may lead to

\footnotetext{
*Correspondence: drliutka@163.com

${ }^{\dagger}$ Equal contributors

${ }^{2}$ Center of Joint Diseases, Tianjin Hospital, Tianjin 300211, China

Full list of author information is available at the end of the article
}

a longer hospital stay, increasing the risk of deep vein thrombosis (DVT) and subsequent surgical procedures, and increasing the healthcare economic burden [4]. Waugh and Stinchfield reported lower infection rates when drainage was used, and closed-suction drainage systems, which theoretically decrease the risk of hematoma formation and wound tension, are used as a routine procedure to decrease the possibility of prolonged wound drainage or infection [5]. Koyano et al. evaluated periwound skin temperature by thermography, finding that skin temperature was lower in the drainage side, which suggested that drainage can suppress inflammation [6]. In turn, this may promote wound healing and functional joint recovery [7]. Conversely, not all the studies have found similarly promising improvement, with differences not observed between groups with or without closedsuction drainage [5, 8-10]. With results on the use of drainage remaining controversial, accurate information is
C Biomed Central

(c) 2015 Cao et al. Open Access This article is distributed under the terms of the Creative Commons Attribution 4.0 International License (http://creativecommons.org/licenses/by/4.0/), which permits unrestricted use, distribution, and reproduction in any medium, provided you give appropriate credit to the original author(s) and the source, provide a link to the Creative Commons license, and indicate if changes were made. The Creative Commons Public Domain Dedication waiver (http://creativecommons.org/publicdomain/zero/1.0/) applies to the data made available in this article, unless otherwise stated. 
required in order to fulfill patient expectations and improve outcomes [11-12]. It has been reported that clamping drainage can reduce blood loss and the need for blood transfusion after total knee arthroplasty (TKA) [13]. No similar reports concerning the application of clamping drainage in THA could be found. Therefore, this study was conducted to clarify whether clamping drainage for $6 \mathrm{~h}$ postoperatively can contribute positively to the postoperative management of cementless THA, by reducing blood loss and minimizing postoperative wound complications.

\section{Materials and methods}

A randomized controlled prospective study was conducted. Our research had ethical approval by Tianjin Hospital Ethical Approval Committee, with written informed consent about the benefits and risks obtained from all patients. Patients with hip OA or femur head necrosis who were subjected to unilateral primary total hip replacement between July 2012 and January 2014 were included. Exclusion criteria included previous history of hip surgery, ongoing infection, and medical conditions contraindicating surgery. Using a random number list, which was generated by computer and offered to every patient, we randomly allocated patients who meet inclusion criteria to either the flexion group or the extension group. The surgeon who provided surgery did know whether the drainage tube was clamped or not. Tube clamping was finished by another member of the study. Patients did not know why their drainage tube was clamped or not. All agents for anticoagulation and antiplatelet were changed to low molecular weight heparin 5 days before admission. The anticoagulation was terminated 1 day before surgery. All patients received THA at the lateral decubitus position via posterolateral approach under spino-epidural anesthesia performed by the same group of surgeons. Cefazolin $(1.0 \mathrm{~g})$ was used as routine antibiotic prophylaxis $30 \mathrm{~min}$ prior to skin cut. Cementless hip prostheses (Link, Hamburg, Germany) were used. Short external rotator muscles were closed after the surgical procedure and the wound closed with a suction tube placed under the deep fascia. At this point, the patients were randomized into either the non-clamped drainage group or the clamped drainage group based on formal randomization and concealed allocation by another researcher, and the suction tube of the patients in the clamped drainage group was clamped for the first $6 \mathrm{~h}$ postoperatively. Venous thromboembolism prophylaxis was carried out in the form of subcutaneous low molecular weight heparin $(0.4 \mathrm{~mL})$ during the remaining hospital stay, and the first dose was administered $12 \mathrm{~h}$ postoperatively. Further mechanical prophylaxis consisted of foot pumps and below-knee thromboembolic deterrent stockings. NSAIDbased analgesia was used to control postoperative pain.
The surgical wounds and drain sites were assessed daily for the presence of persistent bleeding and serous drainage. Indomethacin $25 \mathrm{mg}$ three times daily was administered to all patients to prevent heterotopic ossification. The drainage tube was removed $24 \mathrm{~h}$ postoperatively in both groups. Ankle pumping and quadriceps-setting exercises were encouraged immediately after surgery and extension-flexion movement was performed under the supervision of a physical therapist after removal of the tube. Data collection was then conducted by medical students who were blinded for the study purposes. Blood loss parameters were the main results of interest. The hemoglobin $(\mathrm{Hb})$ level was measured preoperatively and $48 \mathrm{~h}$ postoperatively. Based on the maximum perioperative decrease in $\mathrm{Hb}$ level, total blood loss was calculated according to Gross [14]. Drainage blood was recorded when the tube was removed $24 \mathrm{~h}$ postoperatively. Homologous blood transfusion was performed according to a trigger of $\mathrm{Hb}$ level less than $9 \mathrm{~g} / \mathrm{dL}$. Adverse events during wound healing and recovery were recorded, including hematoma, redness of the incision of more than $1 \mathrm{~cm}$, superficial or deep infection, and DVT during hospital stay or within the initial 6-week postoperative period. Deep infection was diagnosed based on a positive culture from the wound. Any clinical suspicion of DVT was investigated and confirmed by a Doppler ultrasound. Statistical analysis was conducted with SPSS v. 17.0 (SPSS Inc., Chicago, IL, USA) statistical software. Continuous data was expressed as mean \pm standard deviation and tested with Student's tests for difference. Categorical data was analyzed using chi-square tests. A two-sided $p<0.05$ was considered to be statistically significant.

\section{Results}

A total of 44 patients were recruited into the study. There were 15 women and seven men in the clamped group, with mean age of $73.6 \pm 5.5$ years and with a body mass index (BMI) of $26.8 \pm 2.3 \mathrm{~kg} / \mathrm{m}^{2}$. The non-clamped group consisted of 14 women and eight men with a mean age of $72.6 \pm 4.6$ years and BMI of $27.3 \pm 2.7 \mathrm{~kg} / \mathrm{m}^{2}$. Hip pathology was similar in both groups, consisting of 14 cases with $\mathrm{OA}$ and eight with femur head necrosis in the clamped group, and 16 OA and six femur head necrosis in the other group. Affected side was left for 10 cases and right for 12 in the clamped group, and left for nine cases and right for 13 in the non-clamped group. Preoperative $\mathrm{Hb}$ was $14.5 \pm 2.0$ and $14.1 \pm 2.4 \mathrm{~g} / \mathrm{dL}$ for the clamped and non-clamped groups, respectively. There was no statistically significant difference between the two groups for these parameters. Drainage blood was recorded, and the $\mathrm{Hb}$ level was tested $24 \mathrm{~h}$ after tube removal. Drainage blood measured was $177.3 \pm 18.4$ and $252.2 \pm 50.9 \mathrm{~mL}$ in the clamped and non-clamped groups $(p=0.000)$, with $\mathrm{Hb}$ 
$11.8 \pm 1.6$ and $10.8 \pm 1.3 \mathrm{~g} / \mathrm{dL}(p=0.033)$ for each group. The calculated blood loss volumes were $1090.3 \pm 124.2 \mathrm{~mL}$ for the clamped group and $1223.0 \pm 134.0 \mathrm{~mL}$ for the nonclamped group $(p=0.002)$. Transfusion was performed for one patient in the clamped group and three patients in the non-clamped group which was not a significant difference $(p=0.293)$. For adverse events, there was no serious deep infection or DVT in any cases in either group. One superficial infection, two hematomas and three redness of incision were observed in the non-clamped group, and two superficial infections, four hematomas, and two redness of incision in the clamped group. No statistically significant difference between the two groups was found for adverse events $(p=0.571)$.

\section{Discussion}

As in TKA, the effect of closed-suction drainage on blood loss and wound complication has been debated in total hip arthroplasty. Some randomized studies and meta-analysis have not supported the routine use of drainage $[10,12,15]$. Kim et al. did not find a specific correlation between the incidence of wound complication and the use or non-use of closed-suction drainage [7]. Different types of drainage have been analyzed in TKA with promising effects on reduction of blood loss and the need for blood transfusions [13, 16]. Release of the tourniquet has significant influence on the blood flow in a short time after the reestablishment of blood flow [17]. Therefore, clamping for a short period can provide the same effect as persistent drainage under the compression of an elastic bandage after tourniquet release [16]. THA differs from TKA as it is not possible to compress the wound and use a tourniquet. Local pressure acts to stop blood loss, and clamping drainage postoperatively may result in greater pressure, contributing to hemostasis [18]. Similarly to TKA, the ideal duration of clamping is unclear from the literature, although a longer clamping period is associated with increased problems such as delayed wound healing, skin edge necrosis, hematoma, and increasing risk of infection [16, 19]. An increase in wound problems or postoperative complication was not observed in the clamped group compared with the non-clamped group. An important focus is the balance of reducing blood loss and preventing local accumulation. The most ideal result is less blood loss and need of blood transfusion without increasing complications of the wound healing resulting from hematoma. In our study, 6-h clamping period can reduce postoperative blood loss by $100 \mathrm{~mL}$ without more wound problems. However, the need of blood transfusion was not statistically different. More clamping time may be tested such as 8 or $12 \mathrm{~h}$ for the effect of tube clamping in future studies. Limitations to this study include the short postoperative period under study. As no power calculation was undertaken at the start of this study, there is a high risk of the results being underpowered However, the results were trustable because this study was designed well with high methodological quality and they were discussed honestly. Hip functional recovery was not evaluated, despite reports of higher postoperative $\mathrm{Hb}$ levels correlating with better early functional recovery, higher SF-36 scores, higher patient satisfaction, and shorter hospital stays following THA [6, 14]. No consensus about the effect of different THA types, such as cemented or hybrid, on total blood loss exists, and the effect of clamping [20-22], and limited by the small patient numbers, this study was unable to compared different types of THA. Further studies regarding the benefit of postoperative clamping drainage in patients following differing types of THA, and length of time of clamping, would be useful.

\section{Conclusions}

This study was performed in order to establish if postoperative clamping had an effect on blood loss, postoperative complications, and $\mathrm{Hb}$ levels after cementless THA. The results suggest that clamped drainage for $6 \mathrm{~h}$ postoperatively can reduce postoperative blood loss, without an increase in wound healing complications or other postoperative complications, compared with non-clamped drainage. Although it presented a significant difference, the decrease of blood loss was relatively small and no significant difference in need of blood transfusion, suggesting that the effect of postoperative clamping should be questioned for this type of THA. Further investigation into length of clamping time and the effect of clamping with differing THA types could further inform practice, as well as the effect of clamping on longterm functional outcomes.

\section{Competing interests}

The authors declare that they have no competing of interests.

\section{Authors' contributions}

$J$ conceived of the design of the study. JGC and LW performed the surgery and collected the data and contributed to the design of the study. $J$ and JGC prepared the manuscript. JGC edited the manuscript. All authors read and approved the final manuscript.

\section{Acknowledgements}

The authors are grateful for the support of the Project of Natural Science Foundation of Tianjin (14JCQNJC11700).

\section{Author details}

${ }^{1}$ Department of Sport Injuries and Arthroscopy, Tianjin Hospital, Tianjin 300211, China. ${ }^{2}$ Center of Joint Diseases, Tianjin Hospital, Tianjin 300211, China.

Received: 21 March 2015 Accepted: 9 July 2015

Published online: 25 August 2015

\section{References}

1. Bierbaum BE, Callaghan JJ, Galante JO, Rubash HE, Tooms RE, Welch RB, et al. An analysis of blood management in patients having a total hip or knee arthroplasty. J Bone Joint Surg Am. 1999;81(1):2-10. 
2. Nuttall GA, Santrach PJ, Oliver WC Jr, Horlocker TT, Shaughnessy WJ, Cabanela ME, et al. The predictors of red cell transfusions in total hip arthroplasties. Transfusion. 1996;36(2):144-9.

3. Woolson ST, Watt JM. Use of autologous blood in total hip replacement. A comprehensive program. J Bone Joint Surg Am. 1991;73(1):76-80.

4. Maderazo EG, Judson S, Pasternak H. Late infections of total joint prostheses. A review and recommendations for prevention. Clin Orthop Relat Res. 1988;229:131-42.

5. Waugh TR, Stinchfield FE. Suction drainage of orthopaedic wounds. J Bone Joint Surg Am. 1961;43-A:939-46.

6. Koyano G, Jinno T, Koga D, Hoshino C, Muneta T, Okawa A, et al. Is Closed suction drainage effective in early recovery of hip joint function? Comparative evaluation in one-stage bilateral total hip arthroplasty. J Arthroplasty. 2015 Jan;30(1):74-8. Epub 2014 Aug 12. doi:10.1016/j.arth.2014.08.007

7. Kim YH, Cho SH, Kim RS. Drainage versus nondrainage in simultaneous bilateral total hip arthroplasties. J Arthroplasty. 1998;13(2):156-61.

8. Gonzalez DVA, Slullitel G, Vestri R, Comba F, Buttaro M, Piccaluga F, et al. No need for routine closed suction drainage in elective arthroplasty of the hip: a prospective randomized trial in 104 operations. Acta Orthop Scand. 2004;75(1):30-3.

9. Walmsley PJ, Kelly MB, Hill RM, Brenkel I. A prospective, randomised, controlled trial of the use of drains in total hip arthroplasty. J Bone Joint Surg Am. 2005;87(10):1397-401.

10. Acus RW 3rd, Clark JM, Gradisar IA Jr, Kovacik MW. The use of postoperative suction drainage in total hip arthroplasty. Orthopedics. 1992;15(11):1325-8.

11. Niskanen RO, Korkala OL, Haapala J, Kuokkanen HO, Kaukonen JP, Salo SA, et al. Drainage is of no use in primary uncomplicated cemented hip and knee arthroplasty for osteoarthritis: a prospective randomized study. J Arthroplasty. 2000;15(5):567-9.

12. Widman J, Jacobsson H, Larsson SA, Isacson J. No effect of drains on the postoperative hematoma volume in hip replacement surgery: a randomized study using scintigraphy. Acta Orthop Scand. 2002;73(6):625-9.

13. Stucinskas J, Tarasevicius S, Cebatorius A, Robertsson O, Smailys A, Wingstrand $\mathrm{H}$, et al. Conventional drainage versus four hour clamping drainage after total knee arthroplasty in severe osteoarthritis: a prospective, randomised trial. Int Orthop. 2009:33(5):1275-8.

14. Gross JB. Estimating allowable blood loss: corrected for dilution. Anesthesiology. 1983;58(3):277-80.

15. Kelly EG, Cashman JP, Imran FH, Conroy R, O'Byrne J. Systematic review and meta-analysis of closed suction drainage versus non-drainage in primary hip arthroplasty. Surg Technol Int. 2014:24:295-301.

16. Yildiz C, Koca K, Kocak N, Tunay S, Basbozkurt M. Late tourniquet release and drain clamping reduces postoperative blood loss in total knee arthroplasty. HSS J. 2014;10(1):2-5

17. Yamada K, Imaizumi T, Uemura M, Takada N, Kim Y. Comparison between 1hour and 24-hour drain clamping using diluted epinephrine solution after total knee arthroplasty. J Arthroplasty. 2001:16(4):458-62.

18. Larsson J, Lewis DH, Liljedahl SO, Löfström JB. Early biochemical and hemodynamic changes after operation in a bloodless field. Eur Surg Res. 1977;9(5):311-20.

19. Ryu J, Sakamoto A, Honda T, Saito S. The postoperative drain-clamping method for hemostasis in total knee arthroplasty. Reducing postoperative bleeding in total knee arthroplasty. Bull HospJt Dis. 1997;56(4):251-4

20. Zamora-Navas P, Collado-Torres F, de la Torre-Solis F. Closed suction drainage after knee arthroplasty. A prospective study of the effectiveness of the operation and of bacterial contamination. Acta Orthop Belg. 1999;65(1):44-7.

21. Hays MB, Mayfield JF. Total blood loss in major joint arthroplasty. A comparison of cemented and noncemented hip and knee operations. J Arthroplasty. 1988;3(Suppl):S47-9.

22. Trice ME, Walker RH, D'Lima DD, Morris BA, Colwell CW Jr. Blood loss and transfusion rate in noncemented and cemented/hybrid total hip arthroplasty. Is there a difference? A comparison of 25 matched pairs. Orthopedics. 1999;22(1 Suppl):s141-4.

\section{Submit your next manuscript to BioMed Central and take full advantage of:}

- Convenient online submission

- Thorough peer review

- No space constraints or color figure charges

- Immediate publication on acceptance

- Inclusion in PubMed, CAS, Scopus and Google Scholar

- Research which is freely available for redistribution 